\title{
PENGGUNAKAN OKUPANSI DAN KOMPOSISI KENDARAAN UNTUK MENENTUKAN EKIVALENSI MOBIL PENUMPANG (EMP) PADA LALU LINTAS CAMPURAN DI BUNDARAN EMPAT LENGAN
}

\author{
T. Didi Rosadi ${ }^{1)}$, Sugiarto Sugiarto ${ }^{2)}$, Renni Anggraini ${ }^{3)}$ \\ ${ }^{1)}$ Magister Teknik Sipil, Universitas Syiah Kuala \\ ${ }^{2,3)}$ Jurusan Teknik Sipil, Universitas Syiah Kuala \\ Corresponding email: Teukudidirosadi@gmail.com
}

DOI: http://dx.doi.org/10.29103/tj.v9i2.191

(Received: Maret 2019 / Revised: July 2019 / Accepted: August 2019)

\begin{abstract}
Abstrak
Simpang adalah wilayah bertemunya ruas jalan yang membentuk sedikitnya tiga lengan. Peran simpang terhadap suatu jaringan jalan sangat penting karena simpang berfungsi untuk mendistribusikan arus kendaraan yang bertemu. Komposisi kendaraan yang melalui simpang umumnya bervariasi, masing-masing jenis kendaraan memiliki pengaruh yang berbeda terhadap lalu lintas. Oleh karena itu dibuatlah suatu faktor konversi dari suatu kendaraan ke kendaraan acuan, dalam hal ini kendaraan ringan (mobil penumpang), yang dinamakan dengan Ekivalensi Mobil Penumpang (EMP). Penelitian ini bertujuan untuk menghitung nilai EMP berdasarkan kondisi setempat. Penelitian dilakukan di Bundaran Lambaro, Kecamatan Ingin Jaya, Kabupaten Aceh Besar. Lokasi Bundaran Lambaro yang dilintasi jalan nasional penghubung Banda Aceh dan Medan merupakan daerah yang strategis dalam menopang perekonomian, sehingga perlu dilakukan penelitian tentang analisis EMP di Bundaran Lambaro. Metode perhitungan EMP yang digunakan adalah metode waktu okupansi kendaraan dan komposisi kendaraan. Tujuan menggunakan ke dua metode ini adalah untuk membandingkan nilai hasil dari EMP yang didapatkan dari ke dua metode. Data primer yang diperlukan pada penelitian ini adalah kondisi geometrik simpang, kecepatan setempat yang didapat dengan speed gun, dan waktu okupansi kendaraan dan komposisi kendaraan yang diperoleh melalui ektrak video rekaman drone. Nilai EMP yang diperoleh dari menggunakan metode waktu okupansi dari penelitian ini adalah 0,16 untuk sepeda motor (MC), 0,59 untuk becak motor (RS), 1,07 untuk mobil pick-up, 1,91 untuk kendaraan sedang (MV), dan 3,76 untuk kendaraan berat (HV) sedangkan untuk metode regresi linier adalah 0,20 untuk sepeda motor (MC) dan 2,18 untuk kendaraan berat $(\mathrm{HV})$.
\end{abstract}

Kata kunci: simpang, bundaran, EMP, waktu okupansi, regresi linier

\begin{abstract}
The intersection is the point where the streets cross, forming at least three arms. The intersection plays a pivotal role in distributing the flow of converging vehicles. The composition of vehicles passing through the intersection generally varies. Each type of vehicle tends to gives different effects on traffic. Hence, a conversion factor need to be determined from vehicle and reference vehicle (light vehicle), which called as the Passenger Car Equivalent (PCE). The purpose of this study is to calculate the value of PCE based on local conditions. This study was conducted at the Lambaro Roundabout, Aceh Besar Regency. The Lambaro Roundabout crossed by the national road connecting Banda Aceh and Medan, located in a strategic area which supporting the economy. Thus, it is necessary to conducting the EMP analysis at the Lambaro
\end{abstract}




\begin{abstract}
Roundabout. The method which used in this study are the vehicle's time occupancy method and the composition of vehicles method. The purpose of using these two methods is to compare the results of the EMP which obtained from each method. The required primary data in this study are; the intersection geometric conditions; local speed obtained with speed gun; Passenger Car Equivalent (PCE) and the composition of the vehicles obtained through extracting video recordings from drone. The PCE values obtained from this study are 0,16 for motorcycle (MC), 0.59 for rickshaw (RS), 1.07 for pickup (PU), 1.91 for medium vehicle (MV), and 3.76 for heavy vehicle (HV) while for the linear regression method were 0.20 for motorcycle (MC) and 2.18 for heavy vehicle (HV).
\end{abstract}

Keywords: Intersection, Roundabout, PCE, Time Occupancy, Linear Regression

\title{
1. Latar Belakang
}

Sugiarto et al (2018) mempelajari karakteristik lalu lintas di Bundaran Lambaro, Aceh Besar. Mereka mengalibrasi kembali angka ekuivalensi mobil penumpang (EMP) menggunakan data okupansi yang diobservasi menggunakan drone. menyimpulkan faktor konversi EMP sangat signifikan mempengaruhi dalam analisis kapasitas dan kinerja Bundaran.

Bundaran merupakan daerah jalinan yang mampu mendistribusikan arus lalu lintas dengan volume lalu lintas rendah hingga medium. Pada kondisi arus lalu lintas medium bundaran mampu mengurangi tundaan dan memberikan pergerakan yang aman dibandingkan dengan simpang tak bersinyal. Bundaran juga dapat mengurangi potensi kecelakaan dikarenakan pergerakan kendaraan masuk ke daerah jalinan akan mengalami merging atau weaving dengan kecepatan yang relatif rendah (Troutbeck dan Brilon, 2001). Dewasa ini, bundaran banyak diaplikasikan sebagai alternatif simpang tak bersinyal hampir di berbagai negara baik dengan pengoperasian lalu lintas campuran ataupun lalu lintas homogen. Bundaran memberikan kapasitas lebih baik dibandingkan dengan simpang tak bersinyal pada kondisi volume lalu lintas rendah (Sonu et al, 2016). Pada lalu lintas homogen banyak penelitian terdahulu telah mempelajari karakteristik arus lalu lintas pada bundaran misalnya Chandra dan Kumar (2003), Lee (2015) dan Sonu et al, (2016) namun masih sangat minim studi karakteristik lalu lintas pada bundaran pada kondisi lalu lintas campuran. Kebanyakan studi terdahulu mempelajari karakteristik lalu lintas bundaran dengan mengalibrasi kembali faktor ekuivalensi mobil penumpang dan pengaruhnya pada kapasitas bundaran (Arasan dan Arkatkar (2010), Praveen dan Arasan (2013), Sugiarto et al, (2018)). Roess dkk (2004) mendefinisikan kecepatan sebagai laju pergerakan dalam jarak per satuan waktu. Kendaraan yang bergerak dalam satu aliran lalu lintas sangatlah bervariasi sehingga aliran lalu lintas tidaklah memiliki satu angka kecepatan, namun lebih kepada distribusi kecepatan dari masing-masing kecepatan invidual kendaraan. Mohan dan Chandra (2016:4) mengelompokkan kendaraan ke dalam tujuh kategori berdasarkan ukurannya dan karakteristik operasionalnya. Ke tujuh kategori kendaraan tersebut adalah roda dua atau two-wheeler $(2 \mathrm{~W})$, roda tiga atau three-wheeler (3W), mobil penumpang standar atau car standard (CS), mobil besar atau big car (CB), kendaraan komersial ringan atau light commercial vehicle (LCV), bus, dan kendaraan komersial besar atau heavy commercial vehicle (HCV). Mobil dengan kapasitas mesin melebihi 2500 cc dikelompokkan ke mobil besar. 


\section{Metode Penelitian}

\subsection{Lokasi penelitian}

Penelitian ini dilakukan pada bundaran Lambaro yang berlokasi di Kecamatan Ingin Jaya Kabupaten Aceh Besar. Bundaran ini mempunyai empat lengan simpang, dengan tiga lengan simpang masing-masing memiliki empat lajur efektif bermedian (4/2 D) sedangkan satu lengan simpang lainnya hanya memiliki dua lajur efektif tanpa median (2/2 UD). Lokasi penelitian dapat dilihat pada Gambar 1.

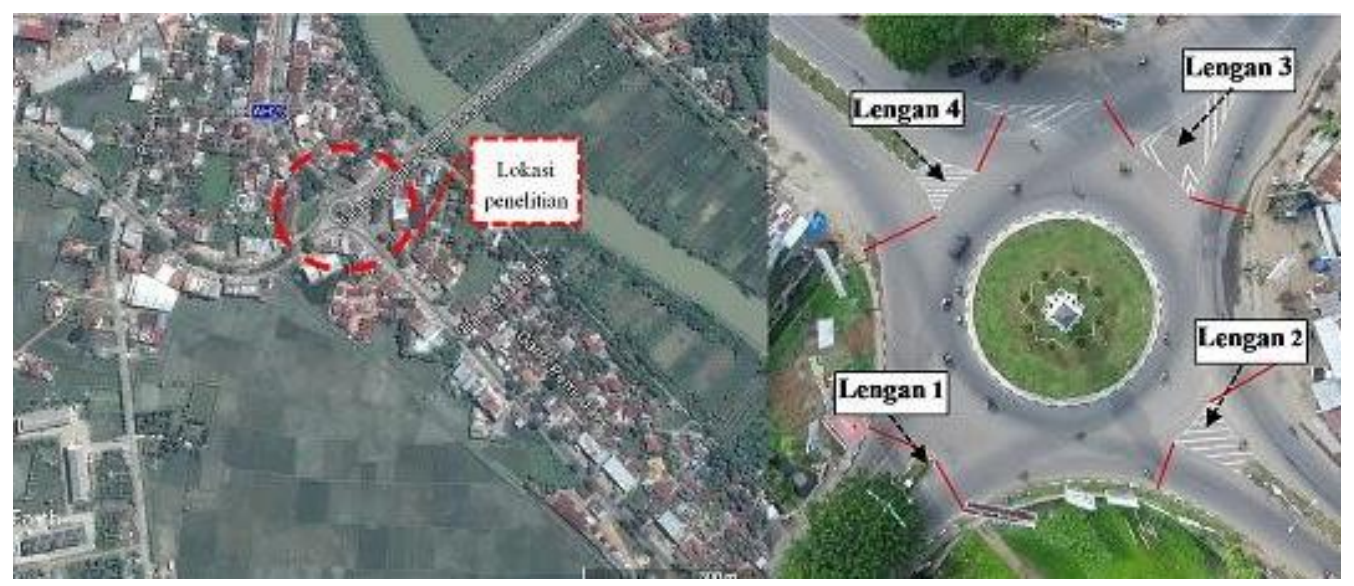

Gambar 1 Lokasi Penelitian di Bundaran Lambaro

\subsection{Pelaksanaan pengamatan dan Pengumpulan Data}

Pengamatan dilakukan pada Senin 5 Juni 2017 dalam rentang jam puncak pagi dan jam puncak sore, Selasa 13 Juni 2017 dalam rentang jam puncak pagi, dan Rabu 14 Juni 2017 dalam rentang jam puncak sore. Pengumpulan data dilakukan berdasarkan pengamatan langsung di lapangan. Hal ini dilakukan untuk mendapatkan data kondisi di lokasi yang akan diteliti. Adapun data yang diambil langsung di lokasi penelitian adalah sebagai berikut:

1. Kondisi geometrik bundaran meliputi lebar lengan simpang, lebar jalinan, panjang jalinan, dan jari-jari bundaran yang diperoleh dengan pengukuran menggunakan pita meter;

2. Kecepatan setempat yang diperoleh menggunakan speed gun;

3. Waktu okupansi kendaraan dan komposisi kendaraan yang didapat dengan mengekstrak rekaman video arus lalu lintas.

\subsection{Kecepatan Lalu Lintas}

Matthew dan Rao (2007) mengemukakan bahwa kecepatan rata-rata waktuadalah rata-rata kecepatan kendaraan yang melewati suatu titik pada periode tertentu. Kecepatan rata-rata waktu merupakan rata-rata aritmatik atau arithmetic mean (AM) dari data kecepatan setempat.Kecepatan rata-rata waktu dirumuskan oleh persamaan 1 .

$$
V_{t}=\frac{1}{\sum f_{i}} x \sum f_{i} \cdot v_{i}
$$

Di mana vi adalah nilai kecepatan setempat, fi adalah Frekuensi, vt adalah Kecepatan rata-rata waktu (time mean speed) 
Rata-rata harmonic atau harmonic mean (HM) dari data kecepatan setempat adalah nilai dari kecepatan rata-rata ruang yang dikalkulasi (Matthew dan Rao (2007) dengan menggunakan persamaan 2.

$$
V_{s}=\frac{\sum f_{i}}{\sum \frac{f_{i}}{v_{i}}}
$$

Di mana vs adalah kecepatan rata-rata waktu (time mean speed), vi adalah nilai kecepatan setempat, fi adalah Frekuensi

\subsection{Waktu okupansi (time occupancy)}

Sonu et al (2016) mendefinisikan waktu okupansi pada bundaran sebagai waktu yang diperlukan oleh suatu kendaraan untuk melintasi area bundaran secara terpisah untuk gerakan belok kiri, lurus, atau belok kanan. Waktu okupansi dihitung mulai dari ujung depan kendaraan memasuki wilayah bundaran sampai dengan ujung belakang kendaraan yang sama keluar dari daerah bundaran tersebut. Suatu kendaraan dianggap telah memasuki area bundaran ketika bumper depan kendaraan tersebut melewati garis/marka henti di bagian pendekat, dan sebaliknya pada saat bumper belakang kendaraan yang sama melewati garis/marka di bagian keluar (exit) maka kendaraan tersebut telah keluar dari wilayah bundaran. Untuk lebih jelasnya dapat dilihat pada Gambar 2. Pada metode ini, kendaraan tidak hanya diklasifikasikan sesuai tipenya, tetapi juga dikelompokkan berdasarkan jenis pergerakannya, dalam hal ini belok kiri, lurus, dan belok kanan.

Persamaan untuk menghitung nilai dari ekivalensi mobil penumpang menggunakan metode waktu okupansi kendaraan dirumuskan oleh Sonu et al (2016). Persamaan ini tertera pada persamaan 3.

$$
P C U_{i}=\frac{T_{i}}{T_{c}} x \frac{A_{i}}{A_{c}}
$$

Dimana, PCUi adalah Nilai EMP kendaraan i, Ti adalah Rata-rata waktu okupansi kendaraan i (s), Tc adalah Rata-rata waktu okupansi mobil penumpang standar (s), Ai adalah Proyeksi luasan kendaraan i (m2), Ac adalah Proyeksi luasan mobil penumpang standar (m2).
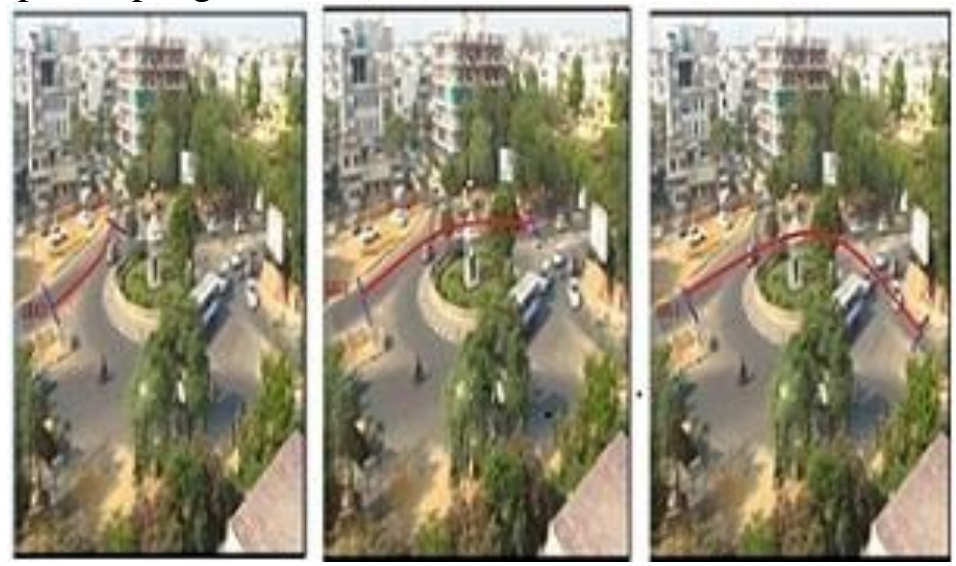

Gambar 2 Penentuan awal dan akhir waktu okupansi kendaraan

Penggunakan Okupansi dan Komposisi Kendaraan Untuk Menentukan Ekivalensi Mobil Penumpang (Emp) Pada Lalu Lintas Campuran Di Bundaran Empat Lengan - T. Didi 


\subsection{Metode Analisis Regresi Linear}

Taylor dan Young (1996) mengembangkan persaamaan analisis regresi linear berganda untuk menghitung arus kendaraan pada periode waktu tertentu. Persamaan tersebut adalah sebagai berikut:

$$
Q_{m}=p c u_{L V} * L V_{m}+p c u_{H V} * H V_{m}+p c u_{M C} * M C_{m}
$$

Dimana, $Q_{m}$ adalah Besarnya arus (smp/jam) pada periode m, $L V_{m}$ adalah Jumlah Light Vehicle pada periode m, $H V_{m}$ adalah Jumlah Heavy Vehicle pada periode m, $M C_{m}$ adalah Jumlah Motorcycle pada periode m, $p c u_{L V}$ adalah Ekivalensi Mobil Penumpang Light Vehicle, $\boldsymbol{p c u}_{H V}$ adalah Ekivalensi Mobil Penumpang Heavy Vehicle dan $\mathrm{pcu}_{M C}$ adalah Ekivalensi Mobil Penumpang Motorcycle

\section{Hasil dan Pembahasan}

\subsection{Kondisi geometrik bundaran}

Data geometrik bundaran diperoleh langsung melalui pengamatan di lapangan. Data yang diukur meliputi lebar lengan simpang, lebar jalinan, panjang jalinan, dan jari-jari bundaran. Pengukuran dilakukan dengan menggunakan pita meter. Sesuai arahan MKJI 1997, jika terdapat parkir di jalan, lebar lengan dikurangi $2 \mathrm{~m}$. Hasil pengukuran kondisi geometrik Bundaran Lambaro dapat dilihat pada Tabel 1 dan pada Tabel 2 adalah dimensi kendaraan berdasarkan jenisnya di Indonesia.

Tabel 1 Geometrik Bundaran Lambaro

\begin{tabular}{lcccc}
\hline Lengan & $\begin{array}{c}1 \\
\text { (arah Banda } \\
\text { Aceh) }\end{array}$ & $\begin{array}{c}2 \\
\text { (arah Bandara } \\
\text { SIM) }\end{array}$ & $\begin{array}{c}3 \\
\text { (arah Kota } \\
\text { medan })\end{array}$ & $\begin{array}{c}\text { ( arah } \\
\text { Meulaboh })\end{array}$ \\
\hline Tipe & $4 / 2 \mathrm{D}$ & $4 / 2 \mathrm{D}$ & $2 / 2 \mathrm{UD}$ & $4 / 2 \mathrm{D}$ \\
\hline Lebar approach & 8,3 & 8,8 & 6,5 & 7,0 \\
\hline Lebar exit & 8,0 & 9,5 & 7,7 & 9,0 \\
\hline Lebar jalinan & 11,7 & 11,0 & 11,0 & 10,2 \\
\hline Panjang jalinan & 33,2 & 22,5 & 28,8 & 33,8 \\
\hline Radius bundaran & & & 12,7 \\
\hline
\end{tabular}

Tabel 2 Dimensi kendaraan berdasarkan jenisnya

\begin{tabular}{ccc}
\hline $\begin{array}{c}\text { Jenis } \\
\text { Kendaraan }\end{array}$ & Lebar (m) & Panjang (m) \\
\hline MC & 0,68 & 1,92 \\
\hline RS & 1,45 & 2,67 \\
\hline LV & 1,66 & 4,19 \\
\hline PU & 1,83 & 3,72 \\
\hline MV & 2,06 & 6,03 \\
\hline HV & 2,43 & 8,52 \\
\hline
\end{tabular}




\subsection{Perhitungan Kecepatan Lalu Lintas}

Dari persamaan 1 dan 2 maka didapatkan nilai kecepatan lalu lintas yang dapat dilihat pada Tabel 3 .

Tabel 3 Profil kecepatan lalu lintas

\begin{tabular}{lcccccc}
\hline Kendaraan & MC & RS & LV & PU & MV & HV \\
\hline Kecepatan minimum & 19,74 & 17,86 & 18,85 & 17,98 & 18,01 & 17,14 \\
\hline Kecepatan maksimum & 26,09 & 22,57 & 24,05 & 22,72 & 23,99 & 21,51 \\
\hline Kec. rata-rata waktu & 23,34 & 20,88 & 22,07 & 21,06 & 21,43 & 19,71 \\
\hline Kec. rata-rata ruang & 22,99 & 20,68 & 21,78 & 20,80 & 21,04 & 19,53 \\
\hline
\end{tabular}

\subsection{Penentuan Nilai EMP dengan Waktu Okupansi}

Perhitungan nilai EMP dilakukan menggunakan metode waktu okupansi kendaraan yang mengacu pada persamaan 3. Hasil perhitungan nilai EMP dapat dilihat pada Gambar 3.

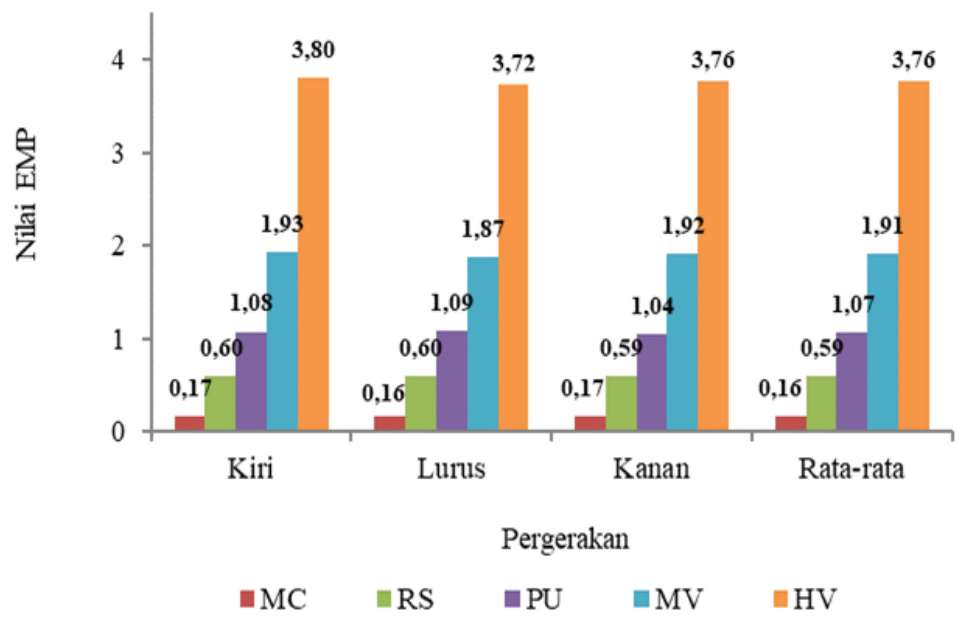

Gambar 3 Nilai EMP dengan metode Waktu Okupansi

Tabel 3 menunjukkan bahwa nilai EMP PU hampir sama dengan nilai EMP LV. Hal ini mengindikasikan meskipun muatannya cenderung berbeda, pengaruh kendaraan pick-up terhadap lalu lintas lebih kurang serupa dengan pengaruh kendaraan ringan. Selain itu, jika mengacu pada MKJI 1997 yang memasukkan kendaraan MV ke dalam HV, maka dengan pendekatan arithmetic mean diperoleh nilai EMP HV sebesar $(1,91+3,76) / 2=2,84$.

Tabel 4 Nilai EMP hasil penelitian di Bundaran Lambaro

\begin{tabular}{cccccc}
\hline Kendaraan & MC & RS & PU & MV & HV \\
\hline Nilai EMP & 0,16 & 0,59 & 1,07 & 1,91 & 3,76 \\
\hline
\end{tabular}

\subsection{Penentuan Nilai EMP dengan Metode Analisis Regresi Linier}

Pada Gambar 4 memperlihatkan perbandingan hasil nilai ekivalensi mobil penumpamg (EMP) dengan menggunakan metode Waktu Okupansi dan metode Regresi linier, maka mendapatkan nilai emp untuk jenis kendaraan ringan (LV), 
sepeda motor (MC) dan kendaraan berat (HV). Untuk nilai emp kendaaraan sepeda motor (MC) nilai terbesar 0,20 dengan menggunakan metode regresi linier dan kendaraan berat (HV) nilai emp 3,76 dengan menggunakan metode waktu okupansi. Untuk deviasi dari nilai EMP hasil perhitungan menggunakan metode waktu okupansi dan metode regresi linier mendapatkan nilai perbedaan sebesar 0,20 untuk sepeda motor (MC) dan 0,42 untuk kendaraan berat (HV).

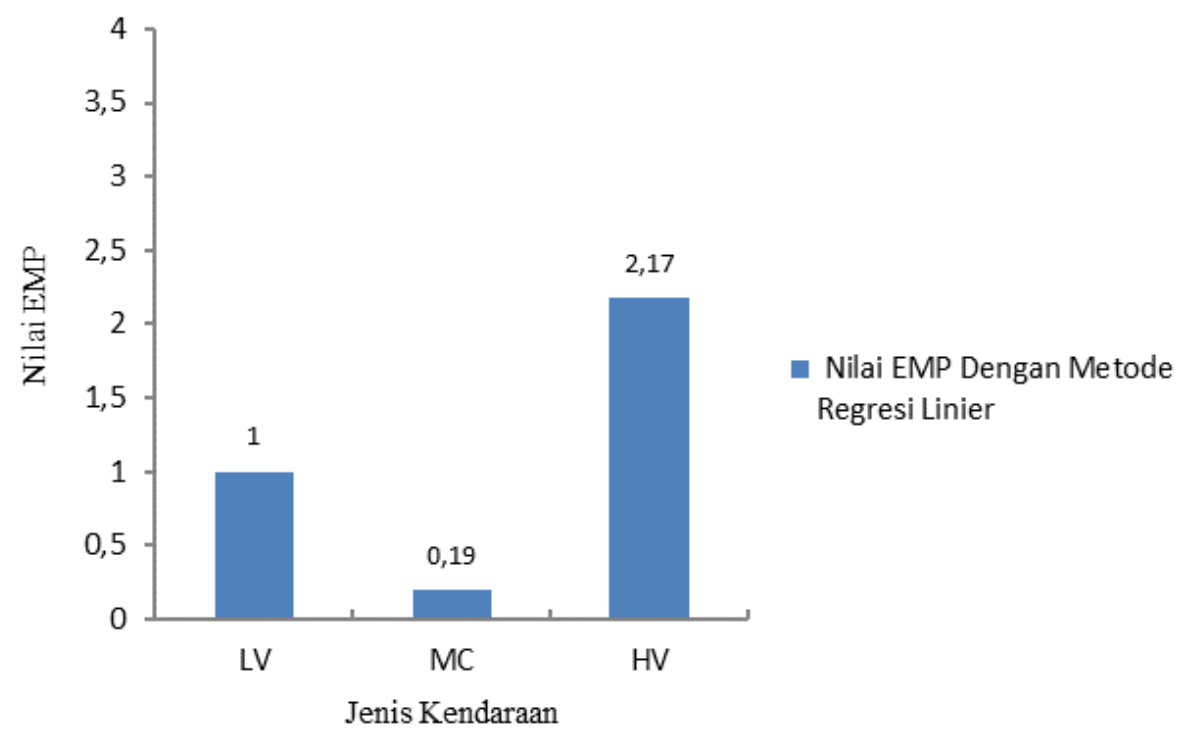

Gambar 3 Nilai EMP dengan metode Analisis Regresi Linier

\section{Kesimpulan dan Saran}

\subsection{Kesimpulan}

Beberapa kesimpulan yang dapat diambil berdasarkan analisis yang dilakukan pada penelitian ini sebagai berikut:

1. Nilai EMP yang diperoleh dari hasil penelitian adalah 0,16 untuk sepeda motor (MC), 0,59 untuk becak motor (RS), 1,07 untuk mobil pick-up (PU), 1,91 untuk kendaraan sedang (MV), dan 3,76 untuk kendaraan berat (HV) dengan menggunakan metode waktu okupansi sedangkan hasil dari menggunakan metode regresi linier diperoleh hasil 0,20 untuk sepeda motor (MC) dan 2,18 untuk kendaraan berat (HV);

2. Rata-rata waktu okupansi terkecil dimiliki oleh kendaraan $\mathrm{MC}$, dan yang terbesar adalah HV. Hal ini sesuai dengan profil kecepatan yang mengungkapkan bahwa di antara semua kendaraan, MC rata-rata kecepatannya paling cepat sedangkan HV bergerak paling lambat.

\subsection{Saran}

Berikut ini diberikan beberapa saran untuk kesempurnaan penelitian diantaranya:

1. Nilai ekivalensi mobil penumpang yang diperoleh dari penelitian ini mungkin dapat dijadikan pertimbangan acuan dalam perhitungan analisis kinerja bundaran di masa yang akan datang, seperti perhitungan kapasitas, derajat kejenuhan, tundaan, peluang antrian, dan sebagainya; 
2. Perhitungan nilai EMP ke depannya diharapkan tidak hanya menggunakan metode yang lazim, akan tetapi dapat dihitung dengan menggunakan metode lain yang masih kurang umum dipakai agar dapat menjadi bahan perbandingan, seperti metode potensi kapasitas (potential capaticy) dan metode rasio antrian yang lewat (queue clearance rate).

\section{Daftar Kepustakaan}

Arasan, V. T., Arkatkar, S. S., 2010. Micro-simulation study of effect of volume and road width on pcu of vehicles under heterogeneous traffic. Journal of Transportation Engineering, 136(12), 1110-1119.

Chandra, S., Kumar, U., 2003. Effect of lane width on capacity under mixed traffc conditions in India. Journal of Transportation Engineering, 129(2), 155160.Garrabrant, R., dkk, 2004, Standard Handbook for Civil Engineers, Fifth Edition, The McGraw-Hill Companies, New York.

Matthew, T. V., dan Rao, K. V. K, 2007, Introduction to Transportation Engineering, NPTEL.

Mohan, M., dan S. Chandra, 2016, "Three Method of PCU Estimation at Unsignalized Intersections", Transportation Letters The International Journal of Transportation Research.

Praveen, P. S., Arasan, V. T., 2013. Influence of traffc mix on pcu value of vehicles under heterogeneous traffc conditions. International Journal for Traffic and Transport Engineering, 3(3), pp. 302-330.

Sonu, M., dkk, 2016, "Time Occupancy as Measure of PCU at Four Legged Roundabouts", Transportation Letters The International Journal of Transportation Research.

Sugiarto, S., Fadhlullah, A., Ruhdi, F., Sofyan, M.S., 2018, Measuring Passenger Car Unit (PCU) at Four Legged Roundabout using Time Occupancy Data Collected from Drone, http://jurnal.unsyiah.ac.id/AIJST/article/view/8587.

Troutbeck R., Brilon W., 2001. Unsignalised Intersection Theory Chapter 8, Traffc Flow Theory, A State-of-the-Art Report, Organized by the Committee on Traffc Flow Theory and Characteristics. 